Proceedings

\title{
The Difference of Propulsive Force between Water Surface and Underwater Conditions in Flutter Kick Swimming ${ }^{\dagger}$
}

\author{
Hiroshi Ichikawa ${ }^{1, *}$, Hirofumi Shimojo ${ }^{1}$, Yasuhiro Baba ${ }^{1}$, Takao Mise ${ }^{1}$, Rio Nara ${ }^{1}$ and \\ Yoshimitsu Shimoyama ${ }^{1}$ \\ 1 Department of Health and Sports, Niigata University of Health and Welfare, Niigata 950-3198, Japan; \\ Emails: shimojo@nuhw.ac.jp (H.S.); baba@nuhw.ac.jp (Y.B.); mise@nuhw.ac.jp (T.M.); \\ nara@nuhw.ac.jp (R.N.); simoyama@nuhw.ac.jp (Y.S.) \\ * Correspondence: ichikawa@nuhw.ac.jp \\ + Presented at the 13th conference of the International Sports Engineering Association, Online, \\ 22-26 June 2020.
}

Published: 15 June 2020

\begin{abstract}
This study investigates differences in propulsive force between the water surface and underwater conditions in the flutter kick swimming technique. The subjects were well-trained university male swimmers. A towing device was set up in a $25 \mathrm{~m}$ swimming pool to measure the towing force and velocity of the swimmer under two conditions: the swimmer was near the water surface and at a depth of $0.60 \mathrm{~m}$. The swimmers performed the gliding trials and the kicking trials with maximum effort with five towing velocities from 1.2 to $2.4 \mathrm{~m} / \mathrm{s}$. The passive drag and the resultant force of the propulsive and drag forces in kick swimming were formulated, respectively. The propulsive force was calculated from the difference between the two formulas. A difference of the propulsive force under conditions in high swimming velocity was observed. This suggests that the water surface condition has advantages of raising the foot above water.
\end{abstract}

Keywords: propulsive force; depth; flutter kick; swimming

\section{Introduction}

Swimmers use their upper and lower limbs to exert a propulsive force. Although the upper limbs play an important role in propulsion in front crawl swimming, the role of the lower limbs and their importance in swimming performance are under discussion. Hollander et al. reported that $11.7 \%$ of propulsion power was an output of kicking by lower limbs [1]. Deschodt et al. illustrated that the contribution of the leg at maximal velocity was approximately $10 \%$ in front crawl swimming [2]. The contribution of the lower limbs in increasing swimming velocity is regarded as a consequence of effect on upper limb movements and maintaining the horizontal alignment of the whole body rather than the exertion of propulsive force directly as discussed in [2-4].

Front crawl swimming is the fastest stroke in competitive swimming. Swimmers exert high propulsive forces to overcome the resistance of water and achieve high swimming velocities. It is expected to find a swimming mechanism and technique that takes account of the possibility of exerting the propulsive force not only in the upper limbs but also in the lower limbs. The purpose of the present study is to investigate differences of propulsive force between the water surface and underwater conditions in flutter kick swimming. 


\section{Material and Methods}

The subjects were five well-trained university male swimmers. The mean and standard deviation of their front crawl swimming velocities was $1.73 \mathrm{~m} / \mathrm{s}$, and $0.07 \mathrm{~m} / \mathrm{s}$, respectively. A towing device (AO-S01, AppliedOffice Inc., Japan, Figure 1) was set up in a $25 \mathrm{~m}$ swimming pool to measure the towing force and velocity of the swimmer under two conditions, namely, the swimmer was positioned near the water surface, and at a depth of $0.60 \mathrm{~m}$. The swimmers performed the gliding trials to keep a streamlined posture (Figure 2a) and the kicking trial with maximal effort (Figure $2 \mathrm{~b}$ ) with towing velocities 1.2, 1.5, 1.8, 2.1 and $2.4 \mathrm{~m} / \mathrm{s}$. The mean towing force was calculated during the most stable $3 \mathrm{~s}$, that is, the range minimizing the variation in each trial.

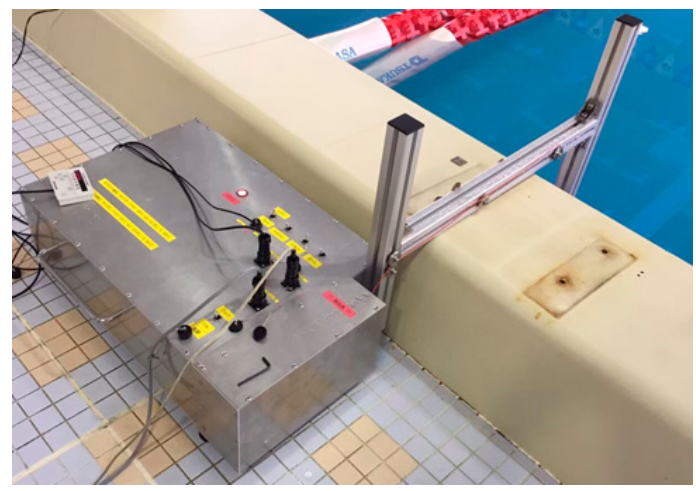

Figure 1. Photographs of the towing device set up in a $25 \mathrm{~m}$ swimming pool.

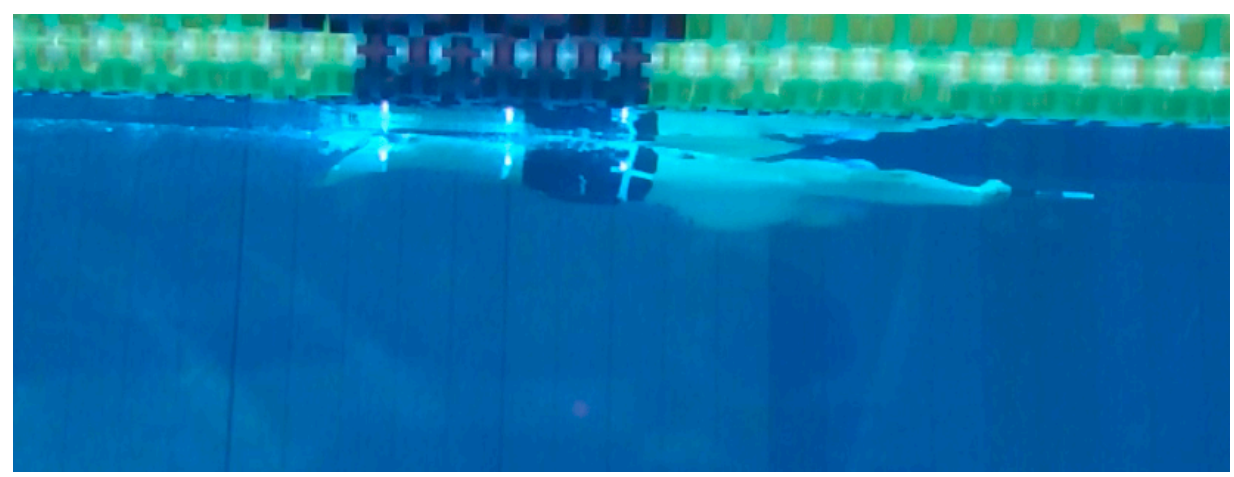

(a) Gliding trial

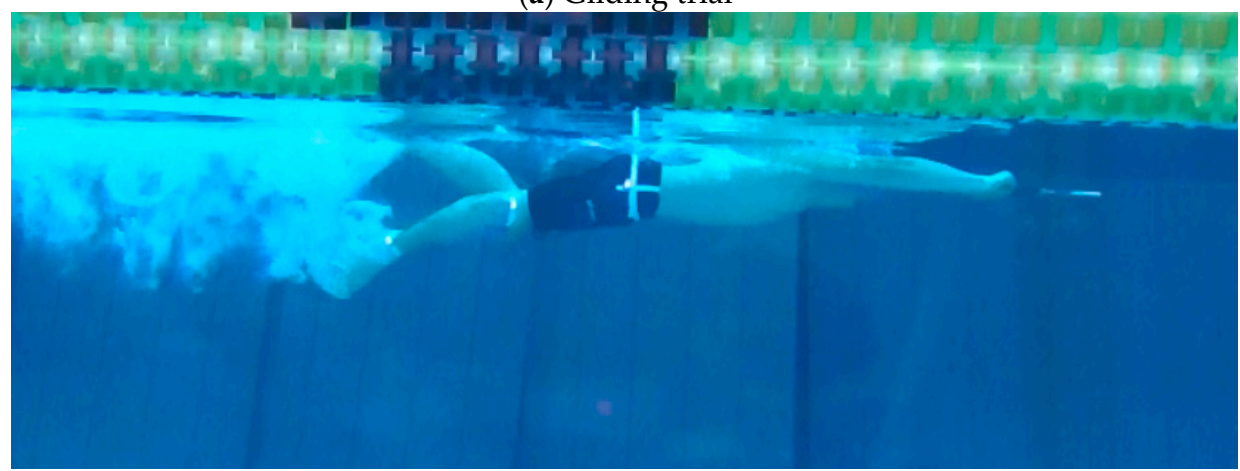

(b) Kicking trial

Figure 2. Photographs of a swimmer in the water surface condition. (a) Gliding trial; (b) Kicking trial.

In the gliding trials, the measured towing force equilibrates the drag force of the swimmer's whole body because swimmers do not exert propulsive force. The drag force is known as passive drag, and formulated as an exponential equation:

$$
F_{\text {drag }}=A v^{b},
$$


where $v$ represents swimming velocity, $A$ is a coefficient of proportionality and $b$ denotes the exponent value [5]. The parameters $A$ and $b$ were identified using the relationship between the towing velocity and force in the gliding trials.

The equation of motion in the kick trial is given by

$$
m \frac{d v}{d t}=F_{\text {tow }}+F_{\text {prop }}-F_{\text {drag }}
$$

where $m$ is the swimmer's mass, $F_{\text {tow }}$ is the towing force, $F_{\text {prop }}$ is the propulsive force exerted by the swimmer's kicking and $F_{\text {drag }}$ is the drag force on the swimmer's whole body (Figure 3). It was assumed that the drag force in the kicking trial was similar to the passive drag, which was measured as the towing force in the glide trial at the same speed. Each swimmer was towed by the towing device at a constant speed. The propulsive force $F_{\text {prop }}$ is estimated by calculating the difference between the drag force $F_{\text {drag }}$ measuring in the glide trial and the towing force $F_{\text {tow }}$ from the kicking trials. This is expressed as:

$$
F_{\text {prop }}=F_{\text {drag }}-F_{\text {tow }} \text {. }
$$

Because Gatta et al. reported the towing force relative to the velocity during the flutter-kicking towing test showed a linear trend [6]. Thus, the relationship between towing velocity and force was modeled as a linear function:

$$
F_{\text {tow }}=c v+d,
$$

where $c$ is the coefficient of the velocity $v$ and $d$ is a constant. The estimated propulsive force was calculated from the difference between $F_{\text {drag }}$ and $F_{\text {tow }}$.

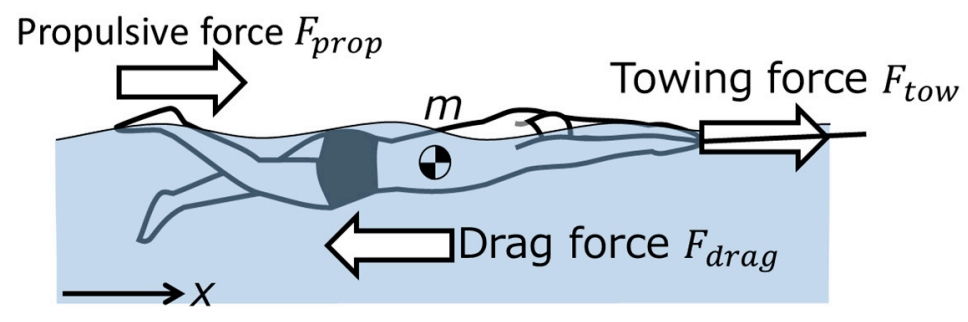

Figure 3. Mathematical model of towing swimming with only the kick technique.

\section{Results}

Figure 4 shows the relationship between the towing velocity and force on the water surface and the $0.60 \mathrm{~m}$ depth conditions. The towing force of the glide trial was larger than the kick trial in the lower swimming velocities, such as 1.2 and $1.5 \mathrm{~m} / \mathrm{s}$, under the conditions of both the water surface and the $0.60 \mathrm{~m}$ depth. The lines representing the glide and kick trials were closer as the swimming velocity increased. The towing force of the kick trial exceeded the glide trial under the $0.60 \mathrm{~m}$ depth conditions at higher velocities, such as 2.1 and $2.4 \mathrm{~m} / \mathrm{s}$. However, four out of five subjects showed that the towing force of the glide trial was consistently larger than the kick trial under the water surface conditions.

Figure 5 demonstrates the comparison of the estimated propulsive force between the water surface and the $0.60 \mathrm{~m}$ depth conditions in each subject. The negative value indicates that the force is exerted backwards. Therefore, it is not propulsive and is a drag force. The propulsive force was the largest at the lowest velocity of $1.2 \mathrm{~m} / \mathrm{s}$ under both conditions. Under the $0.60 \mathrm{~m}$ depth conditions, the faster swimming velocity resulted in the smaller propulsive force. However, the propulsive force did not decrease at higher swimming velocities in the water surface conditions. All subjects showed that the propulsive force under the surface conditions was larger than that of the $0.60 \mathrm{~m}$ depth conditions at swimming velocities greater than $2.0 \mathrm{~m} / \mathrm{s}$. 


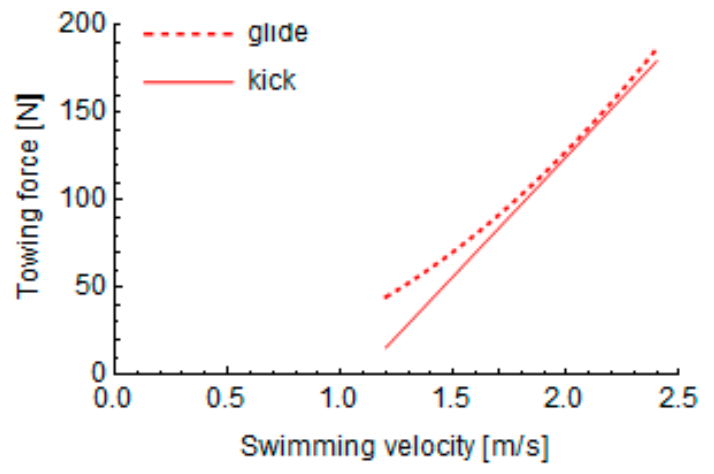

(a) Water surface conditions

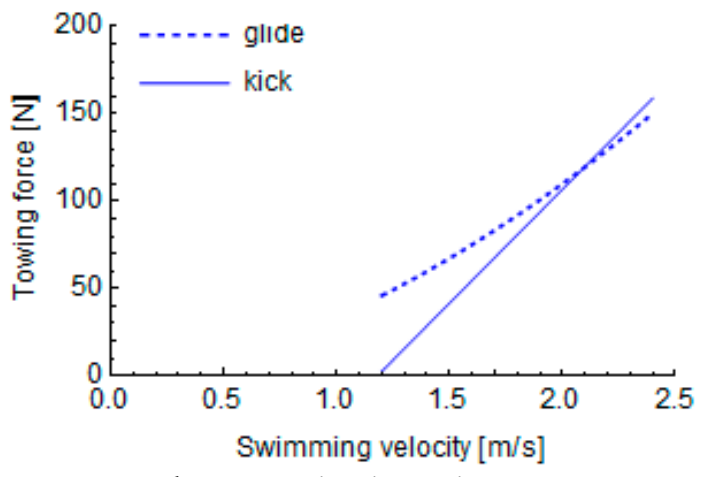

(b) $0.60 \mathrm{~m}$ depth conditions

Figure4. A relationship between towing velocity and force in the glide and kick trials in case of a subject in (a) water surface conditions and (b) $0.60 \mathrm{~m}$ depth conditions.
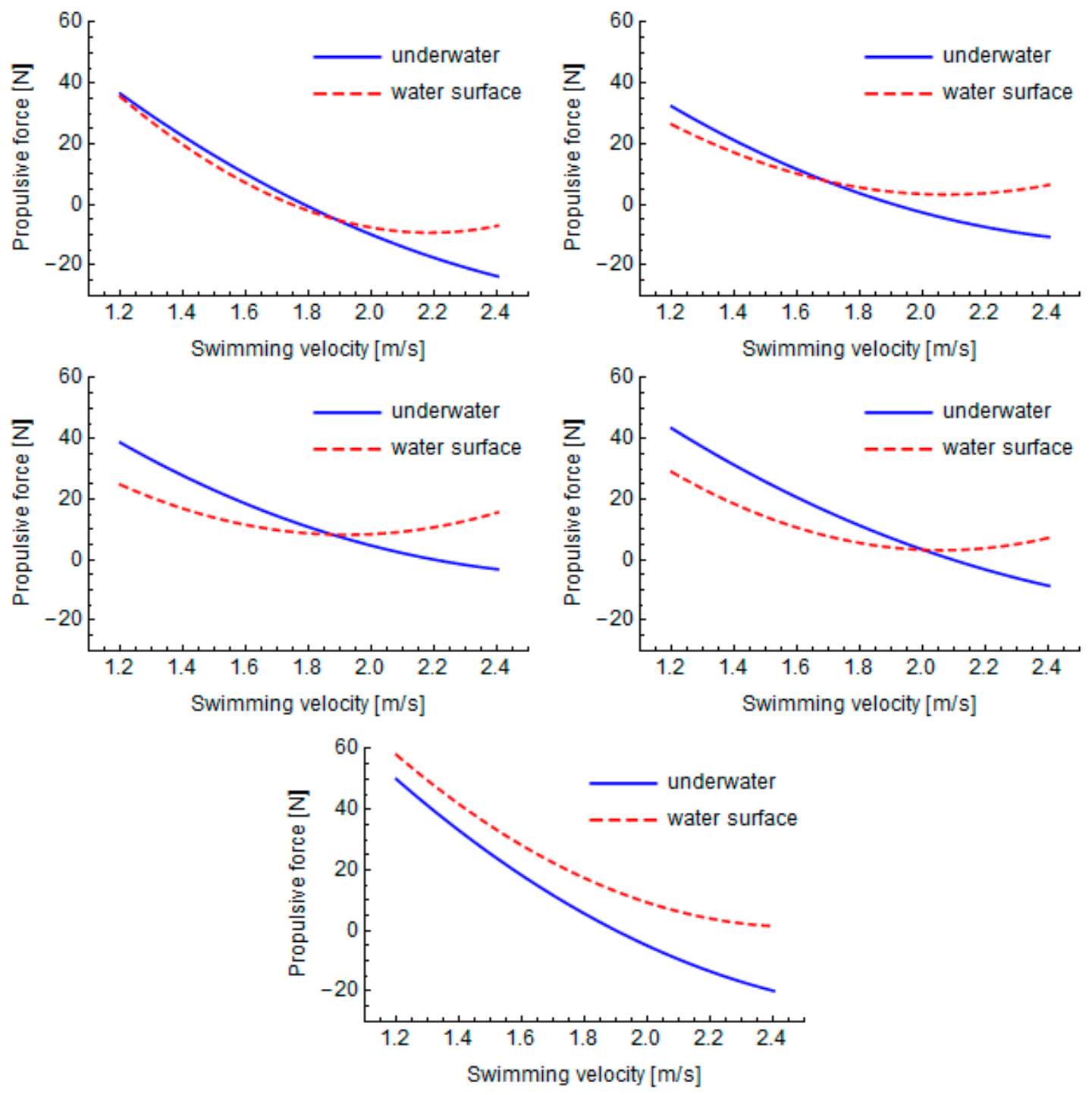

Figure 5. Comparison of the estimated propulsive force between the water surface and $0.60 \mathrm{~m}$ depth conditions in each subject.

\section{Discussion}

The towing force of the kick trial was smaller than that of the glide trial at lower swimming velocities. Assuming that the drag force of the whole body does not change between the glide and kick trials, the decreasing towing force from the glide to kick trial would be a consequence of the 
kicking effect acting as the positive propulsive force. The larger propulsive force of kicking suggested that it is easier to exert a propulsive force using kick motion at lower velocities. Flutter kicking is one of the techniques to swim faster with front crawl swimming. Thus, it is important to discuss the effect of kicking on propulsion at higher swimming velocities. From this study, differences of the towing forces of glide and kick trials were closer to zero in higher swimming velocity with smaller propulsive forces. It was suggested that increasing the swimming velocity would make more difficult to produce the propulsive force for the flutter kicking technique. The suggestion was exactly supported by the observed relationship of velocity and propulsive force under the $0.60 \mathrm{~m}$ depth conditions in this study. On the other hand, this does not seem to apply at higher swimming velocities under the surface conditions. Narita et al. reported that the effect of leg kick depended on the velocity in front crawl swimming, although the upper and lower limb movements increase the resistance compared to the passive conditions [7]. In front crawl swimming, the flutter kick functions to counteract the legsinking moment generated by the hand force [4]. Some studies reported the role and contribution of the kicking motion on propulsion in front crawl swimming. In the study, it was observed that differences of the propulsive force at high velocities between conditions. The differences do not include the effect of arm motion or body rolling. The findings should be explained by water depth and/or kicking motion. The surface conditions would make the foot raised above the water. It was assumed that a swimmer could obtain the two advantages of increasing the foot velocity to kick water backwards and reducing the water drag force on the foot, as the foot moved in the air. However, it was not possible to observe and measure the motion of a swimmer's foot because the water bubbles and splashes reduced the visibility of foot motion remarkably, as shown in Figure 1b. Further methodology to observe/measure a swimmer's motion around the water surface would explain the non-decreasing propulsive kicking force at high swimming velocities.

\section{Conclusions}

In the present study, the propulsive force decreased under the $0.60 \mathrm{~m}$ depth conditions, and the kicking motion would produce a drag force at high swimming velocities. On the other hand, the propulsive force did not decrease under the water surface conditions at high swimming velocities. There are differences in the propulsive force between the conditions. Raising the foot above water in the surface condition would have advantages to increase the foot velocity and reduce the drag force at high swimming velocities.

Author Contributions: Conception and design of study: H. Ichikawa, H. Shimojo, Y. Shimoyama; acquisition of data: H. Ichikawa, H. Shimojo, Y. Baba, T. Mise; data analysis: H. Ichikawa, H. Shimojo; interpretation of data: H. Ichikawa, H. Shimojo, Y. Baba, T. Mise, R. Nara, Y. Shimoyama. Drafting the manuscript: H. Ichikawa; revising the manuscript critically for important intellectual content: H. Ichikawa, H. Shimojo, Y. Baba, T. Mise, R. Nara, Y. Shimoyama. Approval of the version of the manuscript to be published: H. Ichikawa, H. Shimojo, Y. Baba, T. Mise, R. Nara, Y. Shimoyama.

Funding: This work was supported by JSPS KAKENHI Grant Number JP15K01574 and Grant-in-Aid for Research A [R01B13] from the Niigata University of Health and Welfare in 2019.

Conflicts of Interest: The authors declare no conflicts of interest in this paper.

\section{References}

1. Hollander, A.P.; De Groot, G.; Van Ingen Schenau, G.J.; Kahman, R.; Toussaint, H.M. Contribution of the legs to propulsion in front crawl swimming. Swimming Science V, Proceedings of the Vth International Symposium for Biomechanics and Medicine in Swimming, Bielefeld, Germany, Ungerechts, B.E.; Wilke, K.; Reischle, K.; Eds.; Human Kinetics Books: Champaign, IL, 1988, 39-43.

2. Deschodt, V.J; Arsac, L.M.; Rouard, A.H. Relative contribution of arms and legs in humans to propulsion in 25-m sprint front-crawl swimming. Eur. J. Appl. Physiol. 1999, 80, 192-199.

3. Nakashima, M. Mechanical study of standard six beat front crawl swimming by using swimming human simulation model. J. Fluid Sci. Technol. 2007, 2, 290-301. 
4. Yanai, T.; Wilson, B.D. How does buoyancy influence front-crawl performance? Exploring the assumptions. Sports Technol. 2008, 1, 89-99.

5. Toussaint, H.M.; De Groot, G.; Savelberg, H.H.C.M.; Vervoorn, K.; Hollander, A.P.; Van Ingen Schenau, G.J. Active drag related to velocity female swimmers in male and female swimmers. J. Biomech. 1988, 21, 435-438.

6. Gatta, G.; Cortesi, M.; Di Michele, R. Power production of the lower limbs in flutter-kick swimming. Sports Biomech. 2012, 11, 480-491.

7. Narita, K.; Nakashima, M.; Takagi, H. Effect of leg kick on active drag in front-crawl swimming: Comparison of whole stroke and arms-only stroke during front-crawl and the streamlined position. J. Biomech. 2018, 76, 197-203.

(C) 2020 by the authors. Licensee MDPI, Basel, Switzerland. This article is an open access article distributed under the terms and conditions of the Creative Commons Attribution (CC BY) license (http://creativecommons.org/licenses/by/4.0/). 